Dermatology 2011;223:32-35

DOI: $\underline{10.1159 / 000329427}$

\section{Autoimmune Progesterone Dermatitis: Potential Role of Cutaneous Angiogenin Expression?}

\author{
F. Poffet ${ }^{\text {a }}$, S. Abraham ${ }^{\text {a }}$, P. Taramarcaz ${ }^{\text {a }}$, L. Fontao ${ }^{\text {a }}$, L. Borradori ${ }^{\text {b }}$ \\ a Service of Dermatology, Geneva University Hospital, Geneva, \\ and bService of Dermatology, Bern University Hospital, Bern, \\ Switzerland
}

Key Words

Autoimmune progesterone dermatitis - Progesterone • Angiogenin $\cdot$ Epidermal growth factor receptor signaling pathways $\cdot$ Cytokine array

We describe a patient with features typical of autoimmune progesterone dermatitis (AIPD), a rare polymorphous menstrualcycle-related dermatosis [1-6]. To gain better insight into the pathogenesis of this peculiar entity, we here carried out skin testing for hypersensitivity to progesterone as well as a cytokine array study using nonlesional and lesional skin obtained during a flare of her skin disease.

A 30-year-old woman in good general health had a history of a chronic relapsing pruritic eruption involving the waist and the sides of the trunk, evolving since the age of 22 years. The patient described constant relapses of lesions during the second half of the menstrual cycle between days 18 and 21 which regressed spontaneously on day 2 or 3 of the following cycle. The intensity of this cyclical eruption, which was aggravated by fatigue and stressful events, varied with each menstrual cycle with approximately 3 invalidating episodes per year. During the latter, lesions also involved the axillary folds. A topical betamethasone ointment had little effect on her skin eruption. It is noteworthy that marked clinical improvement had been observed when the patient was under oral contraceptives over the past 10 years [gestodenum and ethinylestradiolum (Harmonet $\left.{ }^{\circledR}\right)$, drospirenonum and ethinylestradiolum (Yasmine ${ }^{\circledR}$ )]. More recently, an intravaginal device with etonogestrel and ethinylestradiolum (Nuva Ring ${ }^{\circledR}$ ) also ameliorated her condition.

On examination, the patient presented erythematous papulovesicles and plaques involving the waist and the sides of the trunk (fig. 1a, b). Light microscopy studies of a biopsy specimen (fig. 2) obtained from a lesion of the trunk in the acute phase showed spongiform dermoepidermitis with a perivascular lymphocytic infiltrate composed primarily of CD4-positive cells. Direct immunofluorescence microscopy studies obtained from perilesional skin were negative.
Based on the patient's history and clinical features typical of an AIPD [3], to demonstrate the presence of hypersensitivity to progesterone, we performed patch testing, prick and intradermoreactions with progesterone solubilized in sesame oil as described $[2,3]$.

All these investigations were performed during the follicular phase to avoid interference with endogenous progesterone. While patch and prick testing remained negative, intradermoreaction with micronized progesterone (at a concentration of $50 \mathrm{mg} / \mathrm{ml}$ diluted at $1 / 10$ and $1 / 100$ in sesame oil) elicited both an immediate and delayed reaction.

The test at the 1/10 dilution triggered a very intense immediate reaction at the site of testing with a pruritic plaque of $6 \mathrm{~cm}$ in diameter associated with diffuse lesions (delayed reaction) on the trunk reproducing the usual relapsing dermatosis. The pruritic plaque persisted for 4 weeks. The obtained results were scored as positive provocation test. In contrast, testing with sesame oil alone triggered only a slight erythema consistent with a toxic reaction as previously described [2].

With the informed consent of the patient, we next performed cytokine arrays (Ray Bio Human Cytokine antibody array; C series 2000; panel 6.1, 7.1, 8.1; http://www.raybiotech.com/map_ all_m.asp\#11) using tissue lysates prepared from normal and lesional skin specimens obtained from our patient. Among the 180 tested proteins, we found an increased expression of angiogenin, adiponectin, agouti-related protein, epidermal growth factor receptor (EGFR) and intercellular adhesion molecule 1 in lesional skin compared to uninvolved skin (fig. 3).

AIPD is a rare but characteristic entity, of which at least 70 cases have been described so far [1]. Its clinical presentation is extremely variable with erythematous, macular, papular and/or vesicular rashes [7-9], palmoplantar dyshidrosis [2, 10], erythemamultiforme-like lesion [2-4,11,12], stomatitis [9] as well as urticaria $[13,14]$, angioedema [6] and anaphylactic-like shock [7, 10, 15]. The lesions typically and constantly relapse during the luteal phase of the menstrual cycle. Besides cutaneous testing with progesterone as carried out in our case, other investigations useful for the diagnosis of AIPD include the intramuscular injection of medroxyprogesterone acetate $[4,8]$, a vaginal progesterone provocation test [16], search for circulating antibodies to progesterone [1, 2], basophilic degranulation tests [4], as well as the Elispot assay to identify progesterone-sensitive interferon- $\boldsymbol{\gamma}$-producing cells $[11,17]$.

The pathogenicity of AIPD is unclear. A model predicts an immune reaction to endogenous progesterone during the menstrual cycle [4]. This dermatosis, which is exclusively observed in women during child-bearing years, disappears completely with the menopause, an observation highlighting the importance of hormonal triggers. It has been suggested that previous progesterone
KARGER

(c) 2011 S. Karger AG, Basel

Fax +41 613061234

E-Mail karger@karger.ch

www.karger.com
Accessible online at: www.karger.com/drm 
Fig. 1. a Presence of partially grouped papulovesicular lesions on the abdomen and lateral trunk. b Close-up view of the lesions.
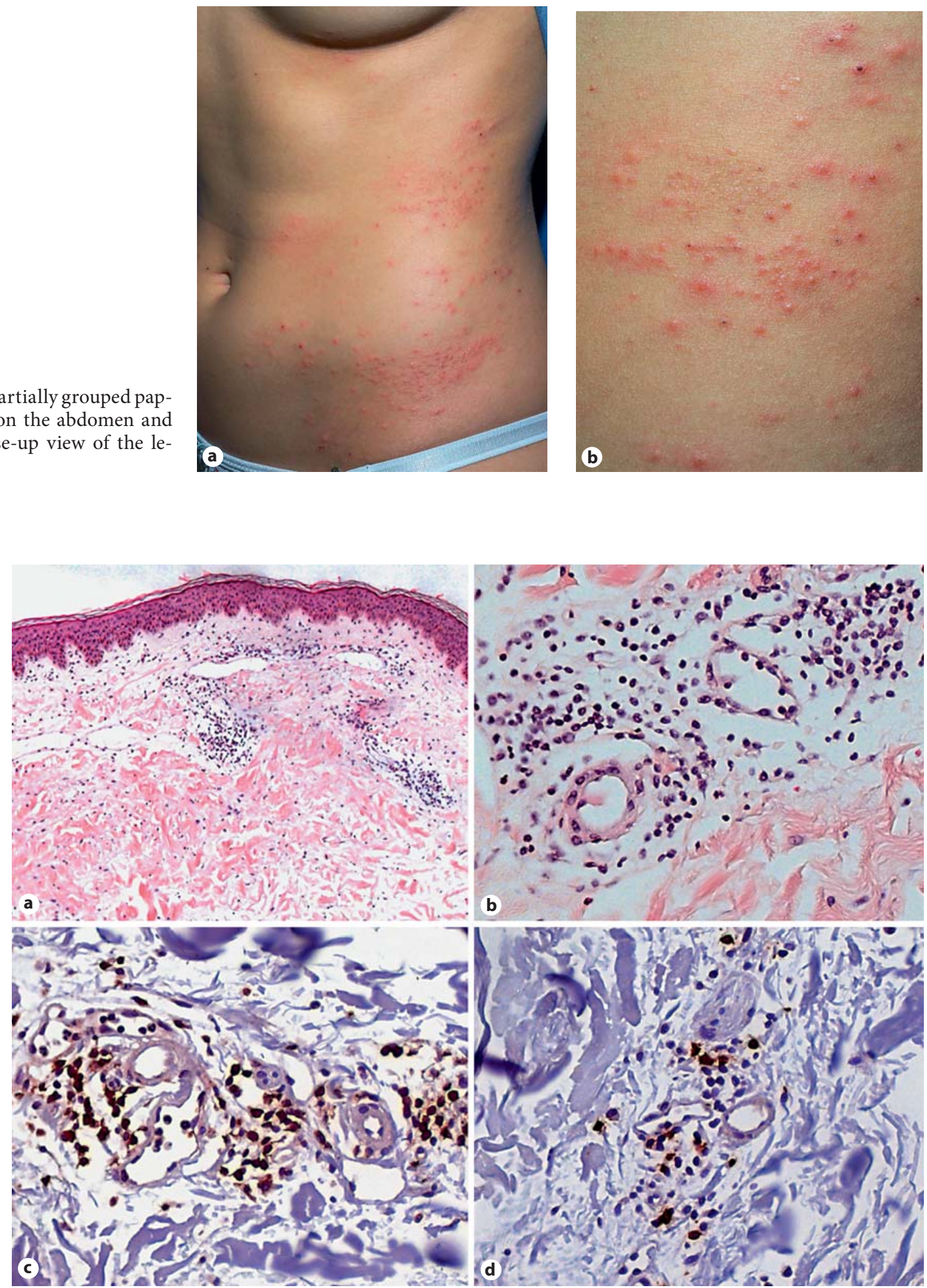

Fig. 2. Histological skin sections (a, b) from a biopsy specimen obtained from the flanks in the acute phase showing spongiform dermoepidermitis with a perivascular lymphocytic infiltrate that contains both CD4positive (c) and CD8-positive T cells (d) with a predominant CD4-positive T cell population. 

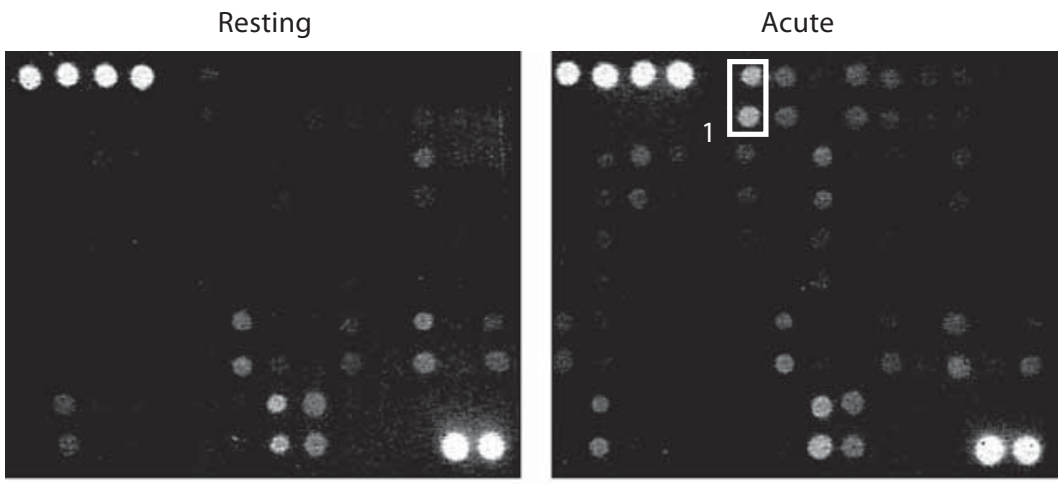

Array 6.1

Fig. 3. Protein arrays (Raybiotech cytokine antibody array 6.1, 7.1, 8.1) were performed on protein extracts prepared from skin biopsies according to manufacturer instructions. Each array was incubated with an identical amount of proteins. After exposure ECL films were digitalized and the image processed in photoshop to normalize, using the positive control as reference as recommended by the manufacturer. Detail on the arrays' composition can be found elsewhere (http://www.raybiotech. com). 1 = Angiogenin; 2 = adipocyte complement-related protein 30/adiponectin; 3 = agouti-related protein; 4 = angiopoietin; 5 = EGFR; 6 = intercellular adhesion molecule 1 .
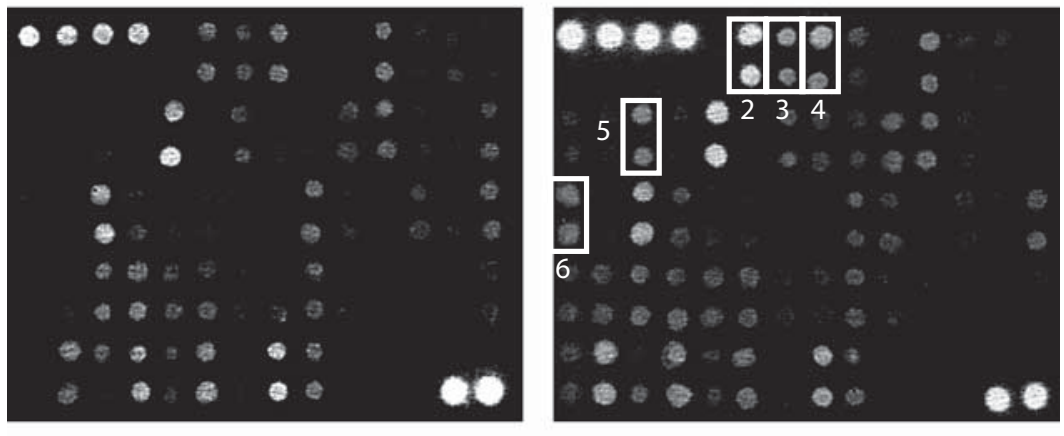

Array 7.1
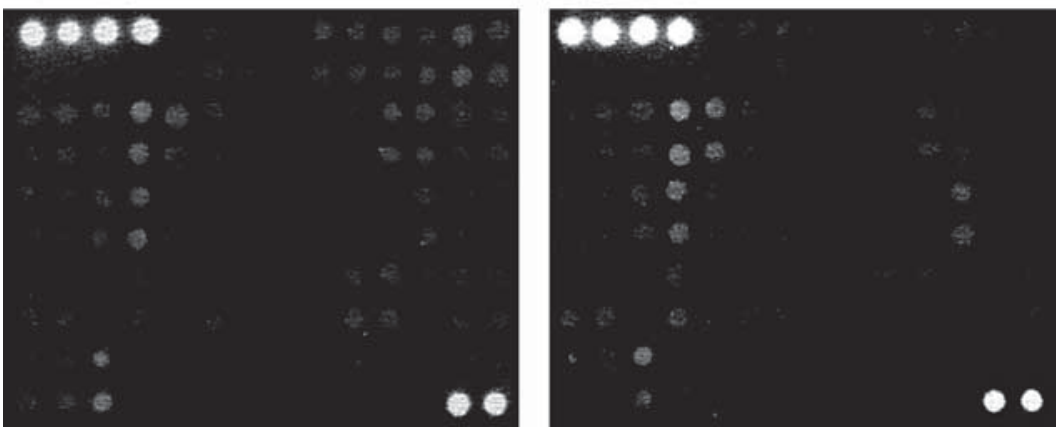

Array 8.1

exposure (i.e. oral contraceptives, intrauterine devices containing progesterone, menarche, pregnancy) results in the stimulation of a hypersensitivity reaction to the endogenous hormones and subsequently leads to overt disease in predisposed patients $[1,2,4$, 15]. In line with this idea, in our case oral contraception was introduced 1 year prior to the development of AIPD. A molecular alteration of the endogenous secreted hormone inducing an immunological response [1] as well as high progesterone levels with exacerbation of type I and III hypersensitivity reactions have also been implicated in AIPD $[1,4,13]$. The fact that the eruption is restricted to the luteal phase with a relatively high progesterone level secreted by the ovary and adrenal gland supports this hypothesis, whereas the concentration-dependent development of the eruption argues against a simple allergic reaction.

To gain better insight into the mechanisms of the disease, we carried out a cytokine array assay (fig. 3). Although there was no clear increase in proinflammatory cytokines (including tumor necrosis factor $\alpha$, interleukins 1 and 17) in lesional skin obtained compared to uninvolved skin during the acute phase, the modest increase of intercellular adhesion molecule 1 expression contributed most likely to the lymphocytic perivascular dermal infiltration (fig. 2).

The presence of angiogenin expression in lesional skin is noteworthy, since this small polypeptide is a potent inducer of angiogenesis and is implicated in endometrial tissue physiology [18]. Furthermore, its expression can be modulated in vitro by progesterone [19]. Recently, angiogenin was found to be expressed in human dermal papilla cells [20]. Since these cells are known to express progesterone receptors [21], it is tempting to speculate that the observed upregulation of angiogenin is controlled by progesterone and is directly implicated in the pathogenesis of AIPD. With regard to the observed upregulation of EGFR in our case, increasing evidence exists indicating that EGFR-linked signaling pathways have a major impact on inflammatory and immune reactions in the skin [22]. Since progesterone is able to activate a number of genes involved in biological processes, including inflammation [23], EGFR-related effects may thus also participate in AIPD physiopathology. 
Finally, the biological relevance of the observed increased expression of adiponectin, a regulator of energy homeostasis [24] of the natural antagonist of melanocortin receptors as well as agouti-related protein [25], remains unclear.

Various treatments have been described in AIPD. Suppression of progesterone secretion is more efficient than corticosteroids or antihistamines. Estroprogestative contraception is the most commonly used therapy $[1,2,5,7,26]$. Other treatments include danazol [27], a synthetic steroid analog that inhibits LH and FSH surge, azathioprin [5], tamoxifen $[9,28]$ as well as oophorectomy $[4,6,14]$. However, LH-RH analogs which induce reversible menopause are often preferred [1,29].

In conclusion, better characterization of the pathways involved in the development and persistence of the cyclical flares of AIPD may open a path for new targeted treatment modalities. Protein and gene expression array data constitute a potential approach to obtain insights into the pathogenesis of this intriguing entity.

\section{References}

$\rightarrow 1$ Dedecker F, Graesslin O, Quereux C, Gabriel R: Autoimmune progesterone dermatitis: a rare pathology. Eur J Obstet Gynecol Reprod Biol 2005;123:117-124.

- 2 Stranahan D, Rausch D, Deng A, Gaspari A: The role of intradermal skin testing and patch testing in the diagnosis of autoimmune progesterone dermatitis. Dermatitis 2006;17:39-42.

- 3 Cocuroccia B, Gisondi P, Gubinelli E, Girolomoni G: Autoimmune progesterone dermatitis. Gynecol Endocrinol 2006;22:54-56.

4 Rodenas JM, Herranz MT, Tercedor J: Autoimmune progesterone dermatitis: treatment with oophorectomy. Br J Dermatol 1998;139:508511.

-5 Kakarla N, Zurawin RK: A case of autoimmune progesterone dermatitis in an adolescent female. J Pediatr Adolesc Gynecol 2006;19:125-129.

-6 O’Rourke J, Khawaja N, Loughrey J, McKenna P: Autoimmune progesterone dermatitis in a parturient for emergency caesarean section. Int J Obstet Anesth 2004;13:275-278.

7 Baptist AP, Baldwin JL: Autoimmune progesterone dermatitis in a patient with endometriosis: case report and review of the literature. Clin Mol Allergy 2004;2:10.

8 Oskay T, Kutluay L, Kaptanoğlu A, Karabacak O: Autoimmune progesterone dermatitis. Eur J Dermatol 2002;12:589-591.

-9 Moghadam BK, Hersini S, Barker BF: Autoimmune progesterone dermatitis and stomatitis. Oral Surg Oral Med Oral Pathol Oral Radiol Endod 1998;85:537-541.

10 Snyder JL, Krishnaswamy G: Autoimmune progesterone dermatitis and its manifestation as anaphylaxis: a case report and literature review. Ann Allergy Asthma Immunol 2003;90:469-477.

-11 Cristaudo A, Bordignon V, Palamara F, De Rocco M, Pietravalle M, Picardo M: Progesterone sensitive interferon-gamma producing cells detected by Elispot assay in autoimmune progesterone dermatitis. Clin Exp Dermatol 2007;32:439-441.

-12 Nasabzadeh TJ, Stefanato CM, Doole JE, Radfar A, Bhawan J, Venna S: Recurrent erythema multiforme triggered by progesterone sensitivity. J Cutan Pathol 2010;37:1164-1167.

13 Wilkinson SM, Beck MH, Kingston TP: Progesterone-induced urticaria, need it be autoimmune? Br J Dermatol 1995;133:792-794.
14 Vasconcelos C, Xavier P, Vieira AP, Martinho M, Rodrigues J, Bodas A, Barros MA, Mesquita-Guimaraes J: Autoimmune progesterone urticaria. Gynecol Endocrinol 2000;14:245-247.

15 Bemanian MH, Gharagozlou M, Farashahi MH, Nabavi M, Shirkhoda Z: Autoimmune progesterone anaphylaxis. Iran J Allergy Asthma Immunol 2007;6:97-99.

16 Nemeth H, Kovacs E, Godeny S, Simics E, Pfliegler G: Autoimmune progesterone dermatitis diagnosed by intravaginal progesterone provocation in a hysterectomised woman. Gynecol Endocrinol 2009;25:410-412.

17 Halevy S, Cohen AD, Lunenfeld D, Grossman N: Autoimmune progesterone dermatitis manifested as erythema annulare centrifugum: confirmation of progesterone sensitivity by in vitro interferon-gamma release. J Am Acad Dermatol 2002;47:311-313.

$\checkmark 18$ Koga K, Osuga Y, Tsutsumi O, Yano T, Yoshino O, Takai Y, Matsumi H, Hiroi H, Kugu K, Momoeda M, Fujiwara T, Taketani Y: Demonstration of angiogenin in human endometrium and its enhanced expression in endometrial tissues in the secretory phase and the decidua. J Clin Endocrinol Metab 2001;86:5609-5614.

19 Koga K, Osuga Y, Tsutsumi O, Yano T, Yoshino O, Takai Y, Matsumi H, Hiroi H, Kugu K, Momoeda M, Fujiwara T, Taketani Y: Demonstration of angiogenin in human endometrium and its enhanced expression in endometrial tissues in the secretory phase and the decidua. J Clin Endocrinol Metab 2001;86:5609-5614.

20 Zhou N, Fan W, Li M: Angiogenin is expressed in human dermal papilla cells and stimulates hair growth. Arch Dermatol Res 2009;301: 139-149.

21 Pelletier G, Ren L: Localization of sex steroid receptors in human skin. Histol Histopathol 2004;19:629-636.

22 Pastore S, Mascia F, Mariani V, Girolomoni G: The epidermal growth factor receptor system in skin repair and inflammation. J Invest Dermatol 2008;128:1365-1374

23 Santos SJ, Aupperlee MD, Xie J, Durairaj S, Miksicek R, Conrad SE, Leipprandt JR, Tan YS, Schwartz RC, Haslam SZ: Progesterone receptor A-regulated gene expression in mammary organoid cultures. J Steroid Biochem Mol Biol 2009;115:161-172.

24 Kadowaki T, Yamauchi T: Adiponectin and adiponectin receptors. Endocr Rev 2005;26:439-451.

25 Olofsson LE, Pierce AA, Xu AW: Functional requirement of AgRP and NPY neurons in ovarian cycle-dependent regulation of food intake. Proc Natl Acad Sci USA 2009;106:15932-15937.

26 Rasi A, Khatami A: Autoimmune progesterone dermatitis. Int J Dermatol 2004;43:588-590.

27 Shahar E, Bergman R, Pollak S: Autoimmune progesterone dermatitis: effective prophylactic treatment with danazol. Int J Dermatol 1997;36: $708-711$.

28 Yotsumoto S, Shimomai K, Hashiguchi T, Uchimiya H, Usuki K, Nishi M, Kanekura T, Kanzaki T: Estrogen dermatitis: a dendritic-cell-mediated allergic condition Dermatology 2003;207:265-268.

29 Banerjee AK, de Chazal R: Chronic vulvovaginal pruritus treated successfully with GnRH analogue. Postgrad Med J 2006;82:e22.

Dr. Frédéric Poffet

Service of Dermatology, Geneva University Hospital

4, rue Gabrielle-Perret-Gentil

CH-1211 Geneva (Switzerland)

Tel. +41 22372 9423, E-Mail frederic.poffet@ hcuge.ch 